\title{
The Transfer and Commercialisation of Technology from South Africa to Foreign Markets in the Financial Services Industry
}

\author{
Francois H. Lubbe, and Alan C. Brent
}

\begin{abstract}
International technology transfer (ITT) processes are complex, risky, and fail often. When financial services organisations have the opportunity to transfer their business model and core technologies to a foreign market, comprehensive technology and market research are compulsory. Numerous applicable theories and models in technology transfer were reviewed to develop such a model. Interviews with key individuals and focus group sessions were used to rank factors that affect the success of ITT in the financial services industry; more specifically the direct short term insurance industry. These success factors were implemented in the developed market evaluation model where the user is required to enter evaluation values for each factor. The evaluation model then delivers a value that represent the market potential. This model can be used to evaluate between one and many potential markets. Two factors an organisation must always be aware of is the influence stakeholders have on the ITT process and what ITT strategy is employed.
\end{abstract}

Index Terms - International technology transfer (ITT), evaluation model, technology strategy, technology management.

\section{INTRODUCTION}

$\mathrm{T}$ HERE is currently a tendency for larger financial firms to globalise their business in other potential foreign markets [1]. Offshoring in the financial services industry will not be easy. Organisations that will benefit the most from offshoring are those organisations that are leaders in their respected sectors. New and unique product innovation is a core component to an organisation's success. This article focuses on the technology transfer in the financial services industry to these potential markets.

The success of a direct short term insurance (DSTI) company is based in its own distinct direct insurance brands and innovative products. The utilisation of call centre technologies and the Internet lowers operational costs. This allows the organisation to focus on marketing and branding its

Manuscript received February 23, 2007. This work was supported in part by Outsurance (Pty) Ltd.

Francois Lubbe is employed by Outsurance, a major insurance company in South Africa; this paper is a result of his research project towards a Masters degree in Technology Management (e-mail: lubbef@out.co.za).

Alan C. Brent is a researcher in the Graduate School of Technology Management of the University of Pretoria, and the Natural Resources and the Environment unit of the Council for Scientific and Industrial Research (phone: 271-242-03929; fax: 271-236-25307; e-mail: alan.brent@up.ac.za). products and/or company. Developing strong brand names and utilising technologies can differentiate a company from its competitor [2]. The DSTI industry is dependent on "internal" and "external" technologies. Internal technologies are those technologies developed by the company, such as intellectual property, whereas external technologies are those technologies that are openly available in the market. These technologies are combined and utilised to develop a unique and profitable product. Internal technologies contribute the most towards a company's competitive advantage whereas external technologies can be duplicated in the industry, but to duplicate a company's competitive advantage is not so easy. Tacit knowledge holds the key to competitive advantage [3]. The DSTI industry is aggressive and motivates innovation by using technology to gain speed in obtaining competitive advantage [2]. The DSTI industry invests in IT, telecommunications and call centre technologies.

The objective of this study was to develop a methodology that will assist organisations in the South African financial services DSTI industry to export core technologies to the global marketplace. This methodology consists of technology evaluation methods, technology transfer methods, market evaluation, and the overall international strategy. The international strategy of an organisation influences the overall technology transfer process.

\section{CONCEPTUAL MODEL}

The organisation is an open system and is influenced by its external environment. A host of external factors influence a firm's choice of direction and action. These factors can be divided into three interrelated subcategories factors in the remote environment, in the industry environment, and in the operating environment [4]. The utilisation of information technology (IT), the Internet and other communication technologies has created more open environments for companies to operate globally.

When considering offshoring, the following tools can be used to develop the suitable international technology transfer strategy: the Generic Value Chain Model [5]; the Technology Balance Sheet [6]; the Technology Space Map (S-L-H map) [7]; and the market and cultural environment analysis approach [8] on technology transfers techniques. 


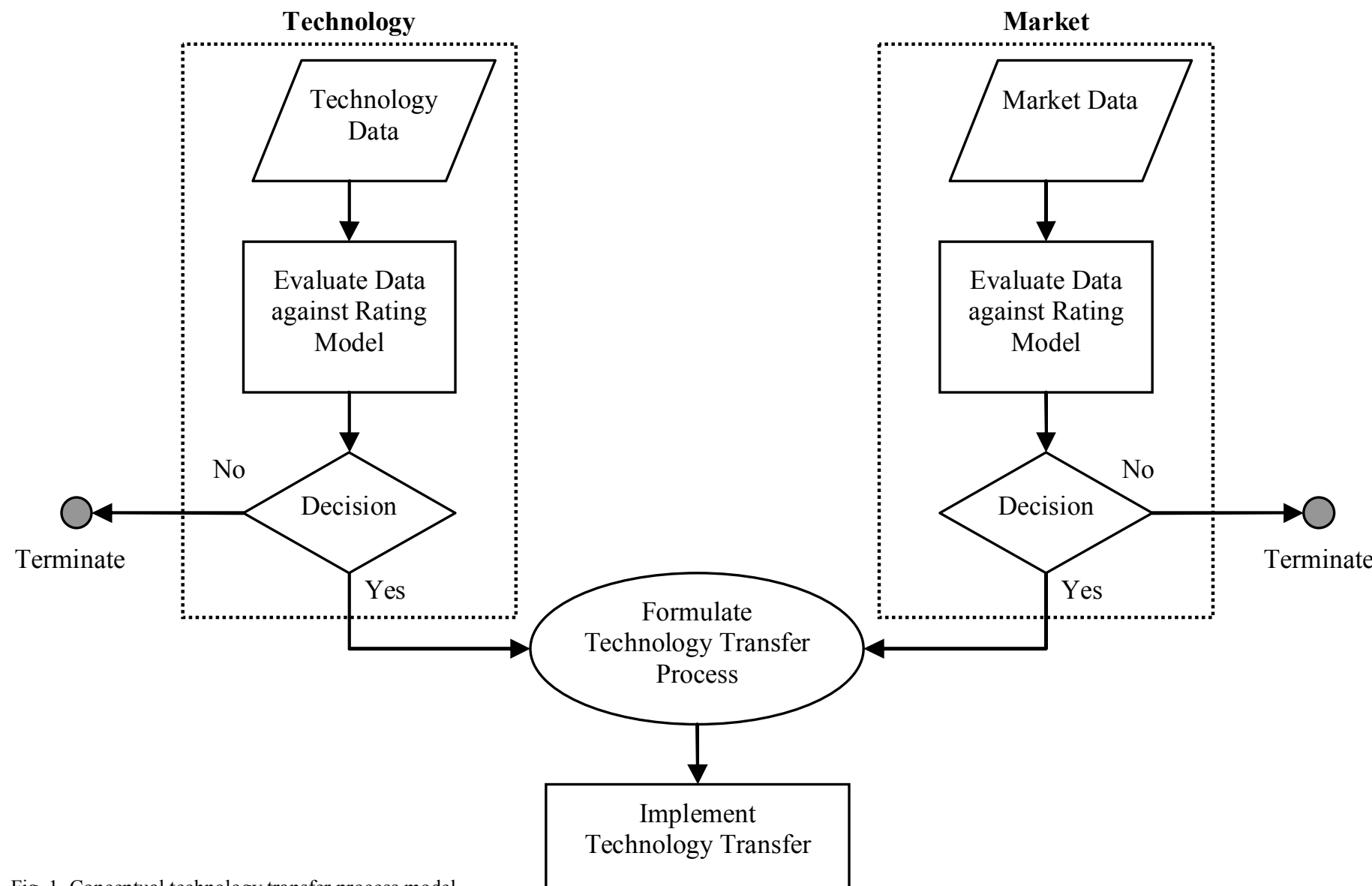

Fig. 1. Conceptual technology transfer process model

TABLE I

Multinational corporations (MNCs) become more dependable on technology to contribute to competitiveness in the global market [8]. Therefore, to understand the factors that influence the transfer of technology become more and more important. An environment-strategy-performance framework that focuses on the micro-level in the external environment has been introduced [9]. From the framework, the general strategy can be formulated of which the organisations strategic profile and its external environment influence the performance. These characteristics form part of the strategic paradigm [10].

\section{A. Technology transfer process model}

The conceptual technology transfer process model is focused on the financial services industry, and specifically the DSTI industry, which presents industry specific indicators to be used to formulate and develop the model. The model is based on a process model or data process diagram [11], which consists of inputs, evaluations, decisions, and outputs. The nature of the proposed international technology transfer process is derived from this concept. The process model presented in Fig. 1 consists of two segments: the technology segment, and the market segment. Each segment is rated against its corresponding environmental factors, which determine the outcome of each market or country.
RATING MODEL - TECHNOLOGY FACTORS

\begin{tabular}{l}
\hline \multicolumn{1}{c}{ Technological Dynamism } \\
\hline 1. Technology transfer \\
2. Adaptability of core technology \\
3. Accessibility of IT (information technology) \\
4. Accessibility of telecommunication technologies \\
5. Accessibility of call centre technologies \\
6. Accessibility of banking technologies \\
7. Internet usage \\
8. Innovation Index \\
\hline Technological Hazards \\
1. Adequate technological and management resources \\
2. Language \\
3. International time differences \\
4. International technology development \\
5. Security (information, technology and IP) \\
6. Disaster recovery plan \\
\hline 1. Corporate policies \\
$\begin{array}{l}\text { 2. Legal policies } \\
\text { 3. Dealing with licenses }\end{array}$ \\
\hline 1. Adequate financial resources (technology transfer cost) \\
\hline \hline
\end{tabular}


TABLE II

RATING MODEL - MARKET FACTORS

Market Dynamism

1. Size of population

2. Size of market

3. Non-life insurance premium written (value)

4. Competitive advantage (ex price or product)

5. Competition: No players

6. Market growth

7. Trading across borders

8. Starting a business

\begin{tabular}{|c|}
\hline Market Hazards \\
\hline 1. Language \\
\hline 2. Employing workers \\
\hline 3. Natural disasters (risk level) \\
\hline 4. Customer behaviour towards the business model \\
\hline Legislation \\
\hline 1. Political stability \\
\hline 2. Paying taxes \\
\hline 3. Protecting investors \\
\hline
\end{tabular}

\begin{tabular}{ll}
\hline & Financials \\
\hline 1. Start-up costs & \\
2. Marketing cost & \\
\hline
\end{tabular}

\section{B. Rating model}

To conduct a comprehensive analysis on each segment (see Fig. 1), it is required to separate these segments and develop two distinct rating models for the corresponding segments: a technology-rating model (Table I); and a market-rating model (Table II). Each rating model consist of two sub-sections: the first section is the "Elimination" section, which contains all the factors that would determine if business can be conducted in that market or country; and the second is the "Measurable" section, which contains all the factors that can be objectively measured to determine the potential of the market and technology transfer. The pre-defined industry-specific factors in each rating model were determined through the Delphi technique [12].

During the technology and market evaluation process, the user is required to enter the corresponding information into the rating model. The elimination outcome acts as a gate or milestone that first must be achieved before any other investigation can take place. To each factor the user is requested to enter yes ("Y") or no ("N"). If the user inserts "N" to any of these factors, the confidence factor will advise that the investigation in the given market should be terminated. If all these factors contain "Y", the confidence factor will advise the user to continue with the next section, the measurable factors. The measurable outcome of the model also requires input values from the user. The value represents the confidence the user has in the given sub-factor or subcategory. The values that are assigned to each sub-factor can only be between 1 and $5(1=$ very low to $5=$ very high $)$. All these inputs are processed and assigned to the measurable outcome. The measurable outcome presents a value between 0 and 10 .

Through the focus group discussions and interviews, it was advised to apply additional weighting to the value the user assigns to each sub-factor. More weighting should be applied to the high end values (ex. 1 and 5) and less weighting should be applied to the more average rated values (ex. 3). The number of sub-factors is represented by " $n$ " where it is 15 for the technology rating model and 18 for the market rating model:

$$
\sum_{i=1}^{n}\left(x_{i}-3\right)^{2}
$$

To ensure that the low confidence rated sub-factors apply enough negative weight to the model, based on the defined formula (1), the following change was required:

$$
\sum_{i=1}^{n}-\left(x_{i}-3\right)^{2}
$$

Where $\mathrm{x}<3$.

Based on equations (1) and (2) the confidence result can be formulated as follows:

$$
f(x, y)=\frac{\sum_{i=1}^{n}\left(x_{i}-3\right)^{2}+\sum_{j=1}^{n}\left(y_{j}-3\right)^{2}}{n}
$$

This value presents a value between -4 and 4 . By using the sum of squares it is possible to obtain the average weighted adjusted factor which represents the market.

To convert the confidence result of equation (3) into the more logical format (between 0 and 10), the formula presented below is applied and this presents the "Measurable Outcome":

$$
\mathrm{g}(\mathrm{x})=10\left(\frac{\mathrm{x}+4}{8}\right)
$$

This factor presents the confidence the model has in the given data. The measurable outcome value results are interpreted as follows:

- Between 0 and 6: terminate the selected market;

- Between 6 and 7.5: more investigations are required on the selected market; investigation; and

- Greater that 7.5: selected market can be considered to transfer technology and/or business.

\section{RESEARCH METHODOLOGY}

Different research methodologies and techniques were used to analyse and assemble the data. The techniques that were used are: interviews with key individuals, focus groups, case studies and experimental studies. To assemble information from an interview or focus group session proved to be very effective. The one-on-one human interaction provides information and advice of a higher quality. The environment is informal, which assist in the discussions in general.

\section{A. Interviews}

Conducting interviews with individuals, who are specialist in their fields, provided specific information on the markets or sectors. These individuals can give critical advice in critical areas of research. It is sometimes difficult to extract the appropriate, required information from a general interview; therefore, it is crucial to design the interview before hand [8]. 
This allows the interviewer to guide the interview in the required direction. It is also necessary to prepare for the interview and know what additional information is required from the interview. Interviews with educated individuals are expensive and time consuming, and conducting a second or even third interview should be avoided because of cost and time.

\section{B. Focus group method}

The focus group method is suitable for "what", "how" and "why" type of questions [13]. These discussions produce data rich in detail that must be considered throughout the research. On the contrary, the focus group consists of executives and other decision-making individuals, and arranging a suitable time can be a challenge on its own. To ensure the success of the discussion session, careful planning must be done in the design of the discussion sessions to ensure a non-threatening environment [14].

The people involved in the focused group discussion session were IT managers, actuaries, technology managers, marketing managers, operational managers, business and general managers and other executives who were all directly involved in the technology and innovation process of the organisation. This provided an adequate number and range of people with diverse experiences covering all aspects of technology and business transfer. The focus group discussions took between one and two hours and it provided enough data applicable to the research problem. To investigate the research problem, the following questions were asked during the discussions:

- What technologies were to be transferred?

- When is the right time to transfer the technology?

- How does the market influence the technology transfer process?

- To which markets can we transfer the technology and business?

- What factors influence the markets and strategy?

- How many resources are required and how does it influence the original company?

During the model development and testing phases, case studies were used in the analyses of results. Pre-post (before and after) case studies were analysed and evaluated against the results produced using the developed model.

\section{RESULTS}

\section{A. Data gathering process}

The international strategist of the DSTI organisation was interviewed five times in which advice were given regarding the research problem. This individual was selected as he is responsible for the international business transfer and has the experience to comment on the research problem. These initial interviews can be seen as quick discussions sessions and took on average 10 to 15 minutes.

After an overall understanding and perspective was formulated of the research problem, many questions such as "Why...?" were raised regarding the research problem. The advice from specialised individuals adds immense value to the uncertainty. Interviews were conducted with individuals who are specialists in the following areas: information technology (2 sessions); business development (1 session); marketing (1 session); actuarial (3 sessions) and international strategies (4 sessions). The questions that were raised to each individual had direct correlation to their respective environment. On average, these interviews took between 30 and 60 minutes. During the focus group discussion sessions, questions were raised to the group of which each member had the opportunity to comment. One of the biggest benefits focus groups entails is that members comment on industries which they are not specialists in but their comments raise other questions which members debate further. These focus group sessions consisted of 5 to 7 members (including the researcher) and on average took between an hour and an hour and a half.

From the initial interview process and focus group sessions questions were asked to individuals and members in which their response (advice) were documented. The interviewers' and members' responses were then processed and a value was allocated between 1 and 10 to each factor that influence the research problem. These values are based on the priority the interviewer and focus group associated with the research factor (see Table III). The values ranged from very low priority (1) to very high priority (10).

During the initial development of the rating models and technology transfer process, the utilisation of case studies and experimental studies guided the research. This technique assists in identifying key factors (positive and/or negative) which influence the rating models and technology transfer pathways. Because case studies can not be generalised [10], finding the most appropriate one was not easy. Case studies and experimental studies were found to be the best scenario analysis techniques in which the market analysis was done. Experimental studies allows for predicting future market performances, where as case studies presents what happened in the past.

\section{B. Proposed theory and methods}

Supplementary to the international technology transfer (ITT), one of the research objectives was the commercialisation of the technology. In the financial services industry the commercialisation of a technology determines the success of the financial services start-up in the newly selected market. Fig. 2 presents a proposed international technology transfer process in the financial services industry. It is important to note how much influence the organisations stakeholders, and more specifically the shareholders and top management, have throughout the ITT process. The ITT strategy must be clearly defined from the start as it will guide the ITT process to obtain the optimal result. 
TABLE III

FACTORS PRIORITISED FROM INTERVIEWS AND FOCUS GROUP SESSIONS

\begin{tabular}{|c|c|c|c|c|c|c|c|}
\hline \multirow[t]{2}{*}{ Factors Investigated } & \multicolumn{5}{|c|}{ Interview Sessions } & \multicolumn{2}{|c|}{$\begin{array}{l}\text { Focus } \\
\text { Groups }\end{array}$} \\
\hline & IV 1 & IV 2 & IV 3 & IV 2 & IV 5 & FG 1 & FG 2 \\
\hline $\begin{array}{l}\text { The adaptability of the core } \\
\text { org. technology }\end{array}$ & 8 & 8 & & & & 6 & 6 \\
\hline $\begin{array}{l}\text { Exporting the core } \\
\text { technology }\end{array}$ & 8 & 8 & 8 & 7 & & 8 & 9 \\
\hline IT infrastructure structures & 9 & 8 & 9 & 7 & & 7 & 7 \\
\hline $\begin{array}{l}\text { Telecommunication } \\
\text { infrastructure structures }\end{array}$ & 9 & 8 & 9 & 7 & & 7 & 7 \\
\hline $\begin{array}{l}\text { Call Centre infrastructure } \\
\text { structures }\end{array}$ & 8 & 7 & 8 & 7 & & 6 & 6 \\
\hline $\begin{array}{l}\text { Banking infrastructure } \\
\text { structures }\end{array}$ & 7 & 7 & 7 & 7 & & & \\
\hline Language & 9 & 9 & 7 & 7 & & 9 & 8 \\
\hline $\begin{array}{l}\text { International technology } \\
\text { development strategy }\end{array}$ & 8 & 8 & 7 & 9 & 7 & 7 & 7 \\
\hline Security of Data & 9 & 7 & 7 & 9 & & & \\
\hline Legislation & & & 9 & 9 & & 8 & 9 \\
\hline Intellectual Property Rights & 7 & 6 & 9 & 9 & & & \\
\hline $\begin{array}{l}\text { The transfer of business } \\
\text { model }\end{array}$ & & 7 & 10 & 10 & 9 & 10 & 10 \\
\hline Market Potential & & & 9 & 9 & & 9 & 9 \\
\hline Market Size & & & 9 & 9 & & 9 & 9 \\
\hline Ease of doing business & & & 7 & 8 & & 7 & 7 \\
\hline Taxes & & & 7 & 8 & & & \\
\hline Employment & & & 8 & 8 & 7 & 6 & 6 \\
\hline Investors Protection & & & 9 & 9 & & & \\
\hline Start-up Cost & & & 5 & 5 & 5 & 5 & 5 \\
\hline Marketing Cost & & & 5 & 5 & 9 & & \\
\hline
\end{tabular}

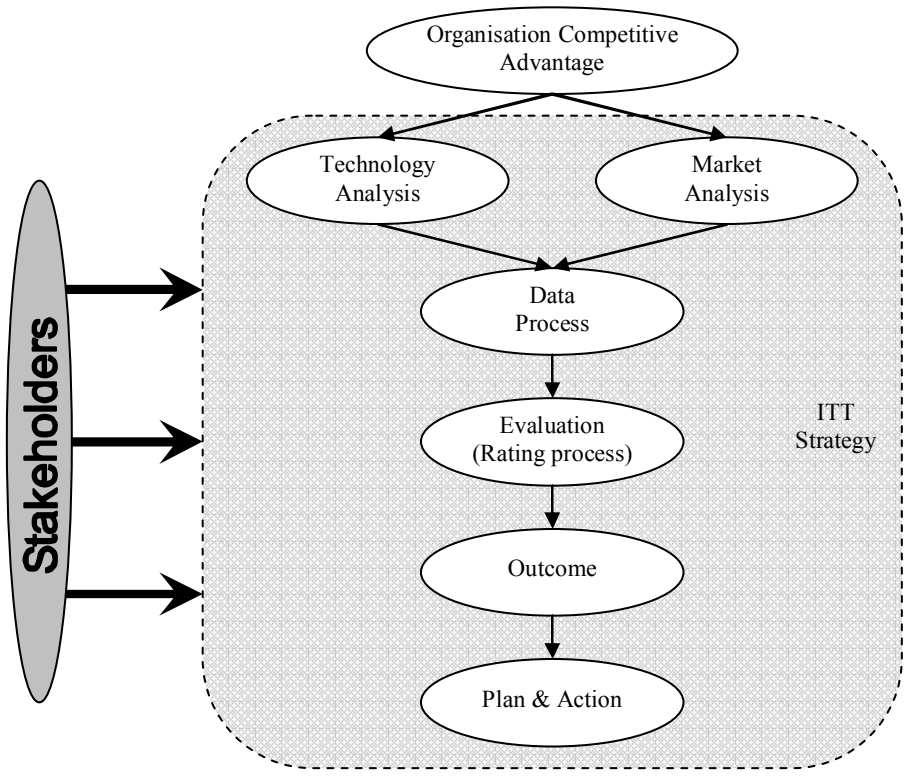

Fig. 2. International Technology Transfer process for the financial services industry

\section{1) Organisational competitive advantage}

When an organisation gets the opportunity to conduct business in a new market, the first step is to determine what gives them a competitive advantage over their competitors in their current market. It has been found that the business model and organisational strategy enhance the success of the business. After these elements are identified, it is essential to known if these elements can be transferred to a new market. These elements will guide the rest of the ITT process.

\section{2) Technology analysis}

It has been proposed that the best time to transfer technology is when the technology is in its growing stage and leading towards its mature stage [15]. The most influential element to the ITT process and ITT strategy is the intellectual property rights (IPR) of the technology that needs to be transferred to another market or country [16], [17]. These IPR's vary from country to country. Developing counties do not have many registered patents and do not have the capital to research and develop their own technologies; therefore, their IPR's are less enforced to allow new technologies to be transferred to them. The United Nations has created a division in 1967 called the World Intellectual Property Organisation (WIPO) that monitors these acts. Developed countries have a different view of the role of IPR. They view IPR as a way of encouraging innovation [18]. They also argue that patents are essential to international economic development because they provide a means of return of investment.

\section{3) Market analysis}

The core elements that were identified, which determine the competitive advantage in the current market, guide the market analysis. It is important that the organisation must first know its current market before it can test its own findings in another market. A detailed investigation on factors such as legislation and the market in whole is essential.

\section{4) Data process}

After all the relevant data on both the technology and market were analysed, the data can be processed. The values assigned to each rating factor are based on the users' confidence as stated previously.

\section{5) Evaluation}

After the data has been processed and the values are entered into the rating model, the rating model calculates a score relative to the information provided (see section II). Table IV presents only those countries which final scores are greater than 7.5 and which qualify to perform the ITT process.

TABLE IV

RANKING RESULTS BASED ON THE RATING MODEL

\begin{tabular}{lcccc}
\hline \hline Country & Technology & Market & $\begin{array}{c}\text { Final } \\
\text { Result }\end{array}$ & Rank \\
\hline United Kingdom & 3.56 & 2.24 & 8.62 & 1 \\
Ireland & 3.39 & 1.65 & 8.15 & 2 \\
Australia & 3.11 & 1.76 & 8.05 & 3 \\
Sweden & 2.83 & 1.47 & 7.69 & 4 \\
France & 2.67 & 1.59 & 7.66 & 5 \\
\hline
\end{tabular}

6) Decision (outcome)

The aim of the evaluation process is to present the elite group of markets, which are rated based on the rating factors. 
The evaluation process assists in the market selection process and presents a value, which indicates the confidence the model has in the market.

\section{7) Plan and action}

Once the market has been identified, the final preparations can start for the ITT. The international technology and business transfer project team can be selected and their full attention can be assigned to the project. The following processes are essential for the ITT:

1. Design and plan the new market penetration strategy;

2. Design and plan the technology and business strategy;

3. Develop technology and business model;

4. Implement technology and business model;

5. Evaluate and test the transferred technologies; and

6. Launch the product.

The organisation's stakeholders play a big roll in the overall ITT (see Fig. 2). They are the decision makers and they will decide if the ITT can, will or needs to take place.

The rating model highlights only the most profound factors that have the biggest influence on the market. The rating model views the ITT in general and do not cater of a specific ITT strategy. The ITT strategy influence the values assigned to each factor. The values allocated to each factor must be consistent to all markets.

\section{CONCLUSIONS AND RECOMMENDATIONS}

The technology transfer needs assessments and implementing activities presented by the Climate Technology Initiative [19] contributed a great deal to the research. Both these introduced models take the following into consideration: the internal and external environments of the organisation; the emphasis on the design and implementation of the technologies; technology transfer across countries; and the influence of stakeholders. One shortcoming these models have in common is the inability to differentiate between developing and developed countries and the influence the ITT strategy has on the ITT process.

During the research design and data analyses, the importance of the ITT strategy became clear. The government and legal systems of a market influence the ITT strategy, and so the rating model (see Tables I and II) takes these elements into consideration. On top of the introduction of a market potential rating model, the proposed ITT model puts more emphasis on technology- and market analysis in terms of a specific market or country. This rating method can be executed to any given market sample, ranging from one to many individual markets or countries.

Throughout the research and data gathering process the research were guided through various uncertainties raised by the stakeholders. These uncertainties and questions where investigated and the findings are described in the paper and in detail elsewhere [20].

\section{A. Recommendations}

The newly presented ITT methodology is recommended to any organisation in the financial services industry that has the opportunity to transfer their technologies and business to a new market (country). For an organisation to be successful internationally, competitive advantage is essential. It is strongly advised to obtain a competitive advantage in the current market before entering the global market. High investment cost is required to enter the global market. If the organisation can't prove their success in the current market, their investors will not be convinced to invest in them.

The financial services industry is globally a relative old and stable industry. If a direct short term insurer wants to grow its market share internationally, high initial investments are required. This influences the ITT strategy as the predicted breakeven point for the new venture will be between 5 and 7 years. This period can even take longer and are dependent on the claims ratio's and market growth in the new market.

Another element that must be highlighted is the time and money it takes to conduct the ITT investigation. It is required to appoint one dedicated investigator, which will do the investigation. One or more senior members need to advise and guide the investigation especially when proposals and business plans are compiled to be presented to the investors. This market investigation can take between 8 to 12 months to complete of which 1 to 2 months will be spent in those final selected markets. After the final decision is made by all the shareholders, an additional 6 to 12 months are needed to finalise the technology and business transfer plans (including the preparation, development and implementation of the technology).

Given the government, population behaviour towards the DSTI industry, market potential and investment cost required, the market identified which will best suit the researched organisation is Australia. The people and culture are very similar to South Africa and will assist in the adoption rate of the new company and products. The clear dominated language in Australia is English spoken by $79.1 \%$ of the population, according to the USA Central Intelligence Agency, which simplifies the language element in ITT. This will have no effect on the current technology and process implemented at the research organisation.

Additional research is recommended into the ITT strategy. It is feasible to investigate in all ITT strategies and present the most appropriate ITT strategy for each investigated market. This will allow the stakeholders to discuss the ITT strategy and comment on future (long-term) organisational strategies.

\section{REFERENCES}

[1] J. Scott. (2006, March 24). Offshoring in the financial services industry: Risk and rewards. PricewaterhouseCoopers, London. [online]. Available: http://www.pwc.com.

[2] MarketResearch.com. (2006, March 29). Direct insurance market assessment 2006. [online] Available: http://www.marketresearch.com.

[3] B. J. Bates, "Information is an economic good: Sources of individual and social value," in The Political Economy of Information, V. Mosco, and J. Wasko, Ed. Wisconsin: The University of Wisconsin Press, 1988.

[4] J. A. Pearce, and R. B. Robinson, Strategic management: Formulation, implementation and control, Ninth Edition, New York: Irwin, 2005.

[5] M. E. Porter, Competitive advantage, New York: Free Press, 1985.

[6] G. de Wet, Corporate strategy and technology management: Creating the interface, Pretoria: University of Pretoria, 1992.

[7] G. de Wet, Technology space maps for technology management and audits, Pretoria: University of Pretoria, 1995. 
[8] A. S. Cui, D. A. Griffith, S. T. Cavusgil, and M. Dabic, "The influence of market and cultural environment factors on technology transfer between foreign MNCs and local subsidiaries: A Croatian illustration," J. Information \& Management, pp. 1-15, 2006.

[9] Y. Luo, and S. Park, "Strategic alignment and performance of marketseeking MNCs in China," Strategic Management Journal, vol. 22, no. 2, pp. 141-155, 2001.

[10] A. Buys, Research methodology, Pretoria: University of Pretoria, 2004.

[11] J. L. Whitten, L. D. Bentley, and K. C. Dittman, Systems analysis and design methods, Firth Edition, New York: McGraw-Hill, 2000.

[12] R. A. Burgelman, M. A. Maidique, and S. C. Wheelwright, Strategic management of technology and innovation, Third Edition, New York: McGraw-Hill, 2001.

[13] R. A. Krueger, Focus groups: A practical guide for applied research, London: Sage, 1998.

[14] N. Nahar, K. Lyytine, N. Huda, and S. Muravyov, "Success factors for information technology supported international technology transfer," $J$. World Business, vol. 41, no. 2, pp. 100-111, 2006.

[15] M. Nieto, F. Lopez, and F. Cruz, "Performance analysis of technology using the $\mathrm{S}$ curve model: The case of digital signal processing (DSP) technologies, Pergamon," J. Technology and Innovation, vol. 18, no. 6 , pp. 439-457, 1998.

[16] L. G. Branstetter, R. Fisman, and F. Foley, Do stronger intellectual property rights increase international technology transfer? Columbia: Columbia Business School, 2003.

[17] P. Magic, International technology transfer \& intellectual property rights, University of Texas, 2003.

[18] D. Rangnekar, D., Project on IPRs and sustainable development, UNCT AD-ICTSD, London: University College London, 2003.

[19] Climate Technology Initiative (2001, January 4). Methods for climate change technology transfer needs assessments and implementing activities: Experiences of developing and transition countries. [online]. Available: http://tclear.unfccc.int/ttclear/html/WshpSeoulPresentations.html

[20] F. H. Lubbe, The transfer and commercialisation of technology from South Africa to foreign markets in the financial services industry, Research project report, Graduate School of Technology Management, University of Pretoria, 2006. 